\title{
Filtros para menores en el consumo de contenidos en dispositivos móviles
}

institucional.us.es/ambitos/

\section{María Sánchez Martínez}

Universidad CEU San Pablo

msanmar.fhum@ceu.es

\section{Teresa Barceló Ugarte}

Universidad CEU San Pablo

tbarcelo@ceu.es

\section{Resumen}

Los límites del entretenimiento audiovisual tradicional, en cuanto a franjas de horario predeterminadas y control del tiempo de exposición a los contenidos, cada vez son más difusos o inexistentes, debido a la aparición de las tabletas y móviles como nuevas pantallas de entretenimiento, que se configuran como un nuevo mercado para los radiodifusores tradicionales. Ante un contexto tecnológico saturado de contenidos y de información, se hace necesario establecer los filtros adecuados para el acceso seguro de los menores a los dispositivos digitales, fundamentalmente móviles, por ser éstos precisamente los que se encuentran más al alcance de la

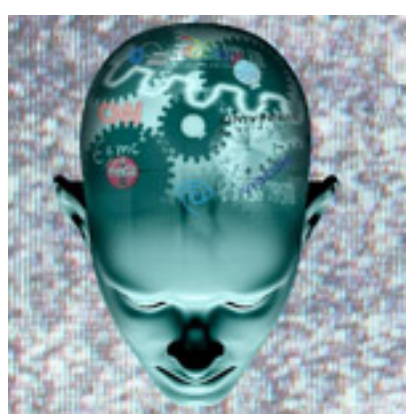
población infantil y en situaciones de menor control parental. Para realizar esta investigación, se han seleccionado diferentes aplicaciones móviles cuyo contenido va dirigido fundamentalmente a menores, con el fin de conocer los posibles filtros necesarios para evitar posibles consecuencias negativas ante la infoxicación.

\section{Palabras clave}

Televisión, menores, infancia, infoxicación, dispositivos móviles.

\begin{abstract}
The boundaries of audiovisual entertainment are changing in its predetermined schedule and in the exposure control content, becoming more shapeless or absent due to the arrival of the tablets and smartphones as new entertainment displays. That means a new market for traditional broadcasters to work. In order to a filled ICT market, it is needed to arrange the appropriate filters for safe access in children and digital devices, because those devices are available anytime and in less parental control situations. To do this research, we selected different mobile applications whose content is aimed primarily to children, in order to know the possible filters necessary to prevent potential negative consequences to the infoxication.
\end{abstract}

\section{Keywords}

Television, children, childhood, infoxication, mobile devices.

\section{INTRODUCCIÓN}

La presencia constante y ubicua de las tecnologías de la información, se ha consolidado también entre los menores, que tienen a su alcance una gran variedad de dispositivos, que les facilitan el acceso a cualquier contenido audiovisual en cualquier momento y lugar.

ÁMBITOS

España es uno de los países con mayor presencia de smartphones (1) a escala mundial y el primero, en porcentaje dispositivo - habitante, en el contexto europeo con una presencia del $66 \%$. En este mismo sentido, un estudio publicado recientemente por el INE (2013) revela que el 91,8\% de los menores de entre 10 y 15 años utilizan Internet de forma habitual y que el $63 \%$ de ellos dispone de teléfono móvil en propiedad. 
En este sentido, no existen frenos en cuanto a la calidad y la cantidad de contenidos que consumen, bien sea a través del acceso a Internet, a las propias aplicaciones móviles que las empresas del sector desarrollan para este tipo de dispositivos, o los propios soportes comercializados bajo la marca de conocidos canales infantiles.

Nuestro objeto de investigación está referido a menores de entre 4 y 10 años, porque es a partir de los 4 años cuando comienzan las calificaciones por edades de la tienda de aplicaciones de Apple (Android sigue otro tipo de clasificación), y a los 10 años los niños reciben su primer teléfono móvil (2) (Orange-Inteco, 2011); momento a partir del cual los padres pierden, en cierto modo, la supervisión sobre el tipo de contenidos y el tiempo que dedican estos menores a sus dispositivos (el $82 \%$ de los menores confirmaban en ese mismo estudio que utilizaban su teléfono móvil en solitario). Se da la paradoja de que es precisamente la seguridad el motivo que alegan principalmente los padres para justificar la posesión de un teléfono móvil por parte de los menores (3), a una edad en la que los amigos empiezan a ocupar una parte importante del ocio y estos dispositivos se convierten en el centro de su vida social.

Cabe destacar que en los últimos años, la presencia de los soportes móviles no ha hecho más que aumentar. La consultora Gartner (4) anunciaba que en el último año la venta de tabletas va a aumentar un 69,8\%, mientras que los ordenadores portátiles y de sobremesa caerán un 7,3 \%. En Estados Unidos (Common Sense Media, 2013) las tabletas (tanto las de Apple como las provistas con otros sistemas operativos) han pasado de estar presentes en un $8 \%$ de los hogares con niños en 2011, a un $40 \%$ en 2013, hecho que se reproduce en los países con más recursos, lo que propicia, sin duda, que los menores estén familiarizados desde edades muy tempranas con los dispositivos móviles y con la tecnología táctil. Si Prensky (2001) se refería a los jóvenes nacidos a partir de 1991 como "nativos digitales" por haber aprendido a manejar los entornos digitales antes que a leer y escribir, esta tendencia se acentúa aún más con las pantallas táctiles de tabletas y smartphones, que muchos niños controlan incluso antes de pronunciar sus primeras palabras, con tiempos de exposición que llegan, en los niños de 0 - 8 años, a unos 15 minutos diarios (Common Sense Media, 2013).

Ser "nativo digital" no significa dominar de forma innata la tecnología o tener un alto nivel de "alfabetización técnica" (Gamero, 2010). Ese conocimiento varía de unos jóvenes a otros, aunque el haber crecido en un contexto digital supone que estén más acostumbrados a utilizar esas herramientas, de las que no todos explotan sus potencialidades. Ese aprendizaje sigue requiriendo una formación y una preparación previas, similares a las que reciben los niños en otras materias. Para Area Moreira (2012:5), el ciudadano del siglo XXI tiene que ser capaz de:

“interactuar con un sistema de menús u opciones mediante un teclado, un ratón o una pantalla táctil, saber navegar a través de documentos hipertextuales sin perderse, conocer los mecanismos y procedimientos para grabar imágenes, procesarlas y difundirlas en un sitio web, poseer las destrezas para buscar y encontrar en la Red aquel dato o información que necesita para resolver un problema, saber discriminar u otorgar significado a las numerosas informaciones que llegan diariamente por múltiples medios, escribir un documento y enviarlo por correo electrónico o por SMS, participar en un foro expresando su opinión, y, en fin, subir fotos, vídeos o presentaciones para compartirlos con otras personas en una red social, etc."

Además, añadiríamos que el ciudadano de nuestro siglo debe tener la habilidad de desarrollar su vida personal de una manera sana y paralela a estos entornos digitales, y eso es una destreza que debería aprenderse desde sus primeros accesos a este medio.

\section{DISPOSITIVOS MÓVILES, NIÑOS Y APPS}

En este contexto que presentamos, donde lo audiovisual y táctil ocupan un lugar privilegiado, el uso que los niños hagan de estos dispositivos, puede tener un profundo impacto en su aprendizaje, comportamiento e incluso en el desarrollo de sus habilidades sociales, por lo tanto no debería ser una cuestión baladí ni alejarse del tratamiento que reciben otros aspectos en el ámbito de la educación.

El hecho de que un tercio de los niños y adolescentes de 9 a 16 años dispongan de su propio perfil en Facebook (Fumero, A. y Espiritusanto, Ó, 2012), pone de manifiesto que algunos niños aprovechan la inexperiencia de sus mayores para burlar los filtros que Internet pone sobre ellos, ya que se trata de una red social que solo permite el acceso de menores a partir de 13 años. 
La falta de una educación específica en los planes de estudios sobre el entorno digital, favorece un desconocimiento, por parte de los jóvenes, de cuestiones legales como la privacidad o la propiedad intelectual, que hacen que tengan una escasa percepción del riesgo que suponen algunas prácticas en la Red. En este sentido, la web desarrollada en España por la Secretaría de Estado de Telecomunicaciones y para la Sociedad de la Información, dependiente del Ministerio de Industria, Energía y Turismo, Chaval.es, nació para concienciar sobre el uso de estas herramientas digitales. Esta página ofrece una serie de consejos (5) para evitar contenidos no apropiados a los menores en tabletas y smartphones; entre las que destacan:

- Probarlas antes,

- No utilizarlas sin supervisión,

- No tener miedo a conocer nuevas tecnologías y compartir la experiencia con los hijos,

- Leer bien la descripción de la aplicación,

- Ver qué otras aplicaciones tiene el desarrollador,

- Dejarse guiar por el icono de la aplicación.

Como desarrollaremos más adelante, la suma de todas las recomendaciones aportan un alto nivel de seguridad para el niño, pero algunas de ellas por separado pueden llevar a confusión o a un entorno poco apropiado según la edad del menor.

La presencia de los menores en el entorno digital entraña riesgos que anteriores generaciones de niños no sufrieron, como puede ser el aumento de los índices de adicción a las nuevas tecnologías (Bringué y Sádaba, 2009: 131-147), o el "tecnoestrés" que define Arenas (2011), así como los distintos tipos de ciberbullying o acoso virtual que han descrito numerosos autores, y que no cesan una vez que el menor se encuentra en un territorio íntimo, como es el hogar, sino que el enemigo ahora también puede estar en el móvil y se transporta en el bolsillo del pantalón.

Sin la pretensión de ser alarmistas, hablar con desconocidos a través de Internet es algo "divertido" para el $12 \%$ de los menores de entre 10 y 18 años y el $11 \%$ declaraba haber recibido "mensajes obscenos o de personas desconocidas" (Bringué y Sádaba, 2009: 195). Un uso incorrecto de las aplicaciones que aquí se analizan, podría favorecer el encuentro con personas alejadas al círculo íntimo de relaciones del menor. Por eso es importante que, además de seguir las indicaciones que ofrece el Ministerio de Industria a través de Chaval.es, no solo se prueben esas aplicaciones antes de dejar jugar al niño, sino que se analice la publicidad o los enlaces externos a redes sociales que aparecen incrustados en estas.

A este efecto, son algunas las marcas que han decidido sacar al mercado tabletas exclusivas para el público infantil (6), que ofrecen entornos seguros a precios asequibles, como son Superpaquito, de la marca juguetera española Imaginarium, o la tableta Clan, del canal televisivo público del mismo nombre.

\section{METODOLOGÍA Y JUSTIFICACIÓN DE LAS VARIABLES}

En primer lugar, justificar la franja de edad de los niños objeto de estudio, que en esta investigación que va de los 4 a los 10 años. Esto es así debido que por un lado, los niños de mayor edad, cuentan en muchas ocasiones con su propio dispositivo (Inteco, 2011: 39), por lo que establecer filtros resulta más difícil para los padres.

Por otro lado, dentro de la franja de los 4 a los 10 años, encontramos que los niños acceden a los dispositivos de sus padres y los utilizan para su propio entretenimiento (Nielsen, 2012).

Son muchas las publicaciones y revistas divulgativas (Ser Padres, Mujer hoy, El País Semanal...) que recogen listas de las aplicaciones más indicadas para los niños o simplemente aquellas de carácter más educativo. Sin embargo, los propios sistemas operativos tienen en sus tiendas, Google Play en el caso de Android y Apple Store para el sistema iOS, listados con las aplicaciones más descargadas ya sean de pago o gratuitas.

Se han seleccionado, de entre las 40 aplicaciones más descargadas, aquellas que por su calificación y 
contenido, podrían estar dentro del rango de edad seleccionado para realizar la investigación.

\subsection{Selección de las aplicaciones}

En un estudio de ComScore de 2013 Spain Digital Future in Focus, unos 4 millones de usuarios, poseen una tablet (diciembre de 2012). En la mayor parte de los casos, independientemente de los fabricantes, los sistemas operativos más utilizados son iOS y Android. Por ese motivo, las tiendas de aplicaciones visitadas para seleccionarlas, pertenecen a estos dos sistemas operativos.

Según un estudio de Nielsen (7) el 70\% de los hogares que tienen hijos menores de 12 años, afirman que los niños las utilizan, asimismo, el $77 \%$ dicen utilizarlas para jugar, un $57 \%$ acceden a aplicaciones educativas. Respecto al comportamiento de los padres, éstos señalan que las tabletas son realmente útiles a la hora de entretener a sus hijos, ya que el $55 \%$ las aprovechan para distraer a los niños mientras viajan, o el $41 \%$ en restaurantes y celebraciones.

Por tanto, es habitual que los niños más pequeños estén ya familiarizados con diversas aplicaciones a través de los dispositivos de sus progenitores. Si bien es cierto que son los padres los que deciden, que aplicaciones descargan para sus hijos, según avanzan en edad, son los propios niños los que se descargan sus propias aplicaciones, más adaptadas a sus preferencias.

La diferencia de volumen de descargas entre las aplicaciones gratuitas y las de pago es mayor en el primero, por eso y por acotar la investigación, solo se han analizado las gratuitas.

Desde las tiendas de aplicaciones, no queda claro, la edad de los usuarios que descargan las aplicaciones, sin embargo dichas aplicaciones sí incluyen una leyenda con la calificación.

En el caso de la App Store de Apple, aparece junto con la descripción de la aplicación, al final: 4+, 9+, 12+, en el caso de aplicaciones para 18+, aparece la siguiente advertencia: "Debes ser mayor de 17 años para descargar esta aplicación".

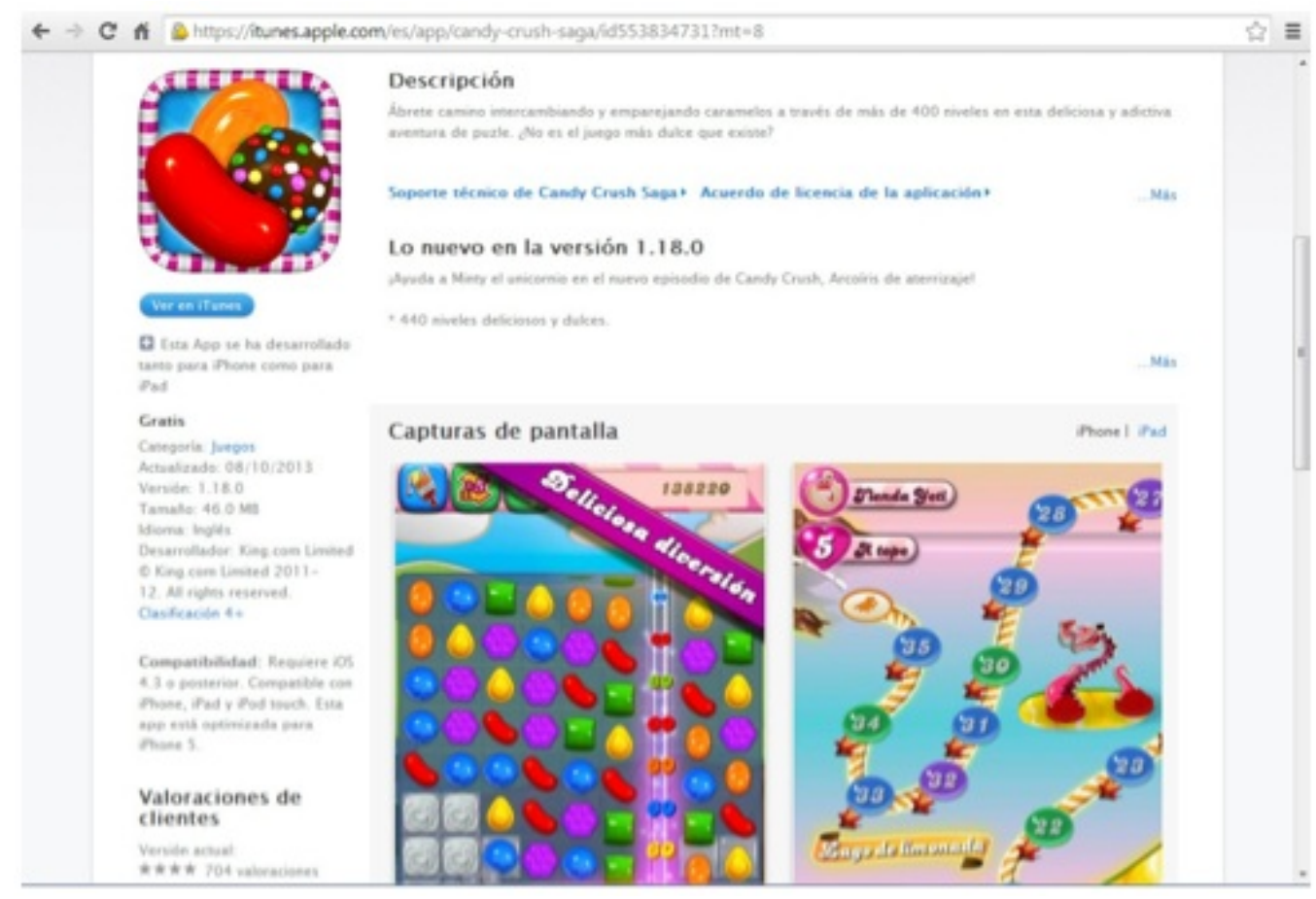

Figura 1: Imagen de la aplicación Candy Crush Saga en su página de descargas para Apple

Para Google Play de Android, la calificación por edades aparece en información adicional, calificando con "todos", "nivel de madurez bajo", "nivel de madurez medio" y "nivel de madurez alto", dejando de esta forma cierta evidencia sobre la edad apropiada para realizar la descarga. 


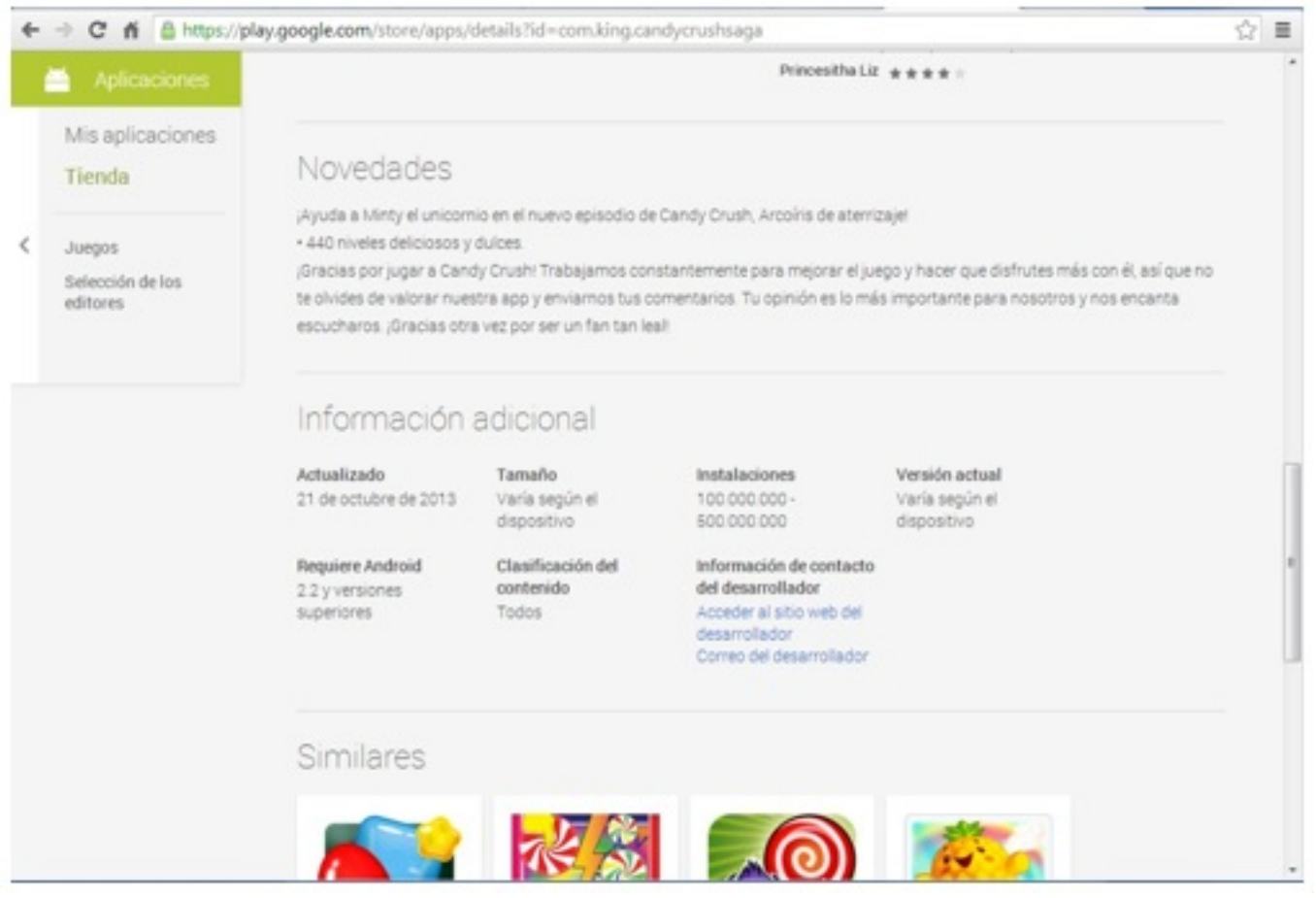

Figura 2: Imagen de la aplicación Candy Crush Saga en su página de descargas para la Google Play

Las aplicaciones (8) aparecen ordenadas en una clasificación por géneros, pero además hay una clasificación que hace referencia a las listas de las más descargadas gratis o de pago.

Es, precisamente en esas listas, de donde hemos seleccionado las aplicaciones analizadas, eligiendo aquellas que por su calificación son susceptibles de ser utilizadas por niños. 
http://dx.doi.org/10.12795/Ambitos.2014.i26.05

\begin{tabular}{|c|c|c|c|c|c|}
\hline $\begin{array}{l}\text { Lugar } \\
\text { en el } \\
\text { ranking }\end{array}$ & $\begin{array}{l}\text { Nombre } \\
\text { aplicación }\end{array}$ & Desarrollador & $\begin{array}{c}\text { Fecha } \\
\text { actualización }\end{array}$ & $\begin{array}{c}\text { Clasificación } \\
\text { de } \\
\text { contenido }\end{array}$ & Tipología \\
\hline 3 & $\begin{array}{l}\text { Turbo } \\
\text { racing } \\
\text { league }\end{array}$ & RikPak & $\begin{array}{c}8 \text { ectubre } \\
2013\end{array}$ & +4 años & Luegos \\
\hline 6 & $\begin{array}{c}\text { Pet rescue } \\
\text { saga }\end{array}$ & $\begin{array}{l}\text { King.com } \\
\text { limited }\end{array}$ & $\begin{array}{c}21 \text { octubre } \\
2013\end{array}$ & +4 años & Juegos \\
\hline 7 & $\begin{array}{c}\text { Crazy } \\
\text { Shave- } \\
\text { Free } \\
\text { Games }\end{array}$ & $\begin{array}{c}\text { Bluebear } \\
\text { Technologies } \\
\text { Ltd }\end{array}$ & $\begin{array}{l}22 \text { octubre } \\
2013\end{array}$ & $\begin{array}{c}+4 \text { años } \\
\text { (pensada } \\
\text { para niños de } \\
6-8 \text { años) }\end{array}$ & Juegos \\
\hline 8 & $\begin{array}{l}\text { Nose } \\
\text { Doctor! }\end{array}$ & $\begin{array}{c}\text { Bluebear } \\
\text { Technologies } \\
\text { Ltd. }\end{array}$ & $\begin{array}{c}18 \text { octubre } \\
2013\end{array}$ & $\begin{array}{c}+4 \text { años } \\
\text { (pensada } \\
\text { para niños de } \\
6-8 \text { años) }\end{array}$ & Juegos \\
\hline 9 & $\begin{array}{c}\text { Candy } \\
\text { crush saga }\end{array}$ & $\begin{array}{l}\text { King.com } \\
\text { limited }\end{array}$ & $\begin{array}{c}\text { 8 octubre } \\
2013\end{array}$ & +4 años & Juegos \\
\hline 13 & $\begin{array}{c}\text { FIFA } 14 \text { by } \\
\text { EA } \\
\text { SPORTS }\end{array}$ & EA Swiss Sarl & $\begin{array}{c}21 \text { octubre } \\
2013\end{array}$ & +4 años & Juegos \\
\hline 14 & $\begin{array}{c}\text { Libii } \\
\text { Hospital }\end{array}$ & $\begin{array}{l}\text { Libii Tech } \\
\text { Limited }\end{array}$ & $\begin{array}{c}22 \text { octubre } \\
2013\end{array}$ & +4 años & Juegos \\
\hline 17 & $\begin{array}{c}\text { CSR } \\
\text { classics }\end{array}$ & $\begin{array}{l}\text { Natural motion } \\
\text { games limited }\end{array}$ & $\begin{array}{c}16 \text { octubre } \\
2013\end{array}$ & +4 años & Juegos \\
\hline 19 & $\begin{array}{c}\text { Halloween } \\
\text { Costume } \\
\text { Party - } \\
\text { Spooky } \\
\text { Salon, Spa } \\
\text { Makeover } \\
\text { \& Dress } \\
\text { Up }\end{array}$ & $\begin{array}{c}\text { Kids Fun Club } \\
\text { by TabTale }\end{array}$ & $\begin{array}{c}23 \text { octubre } \\
2013\end{array}$ & +4 años & Juegos. \\
\hline 20 & $\begin{array}{l}\text { Rolling } \\
\text { Coins }\end{array}$ & $\begin{array}{c}\text { Kakarod } \\
\text { Interactive }\end{array}$ & $\begin{array}{c}19 \text { ectubre } \\
2013\end{array}$ & +4 años & Juegos. \\
\hline
\end{tabular}

Tabla 1. Aplicaciones iOS gratuita 
http://dx.doi.org/10.12795/Ambitos.2014.i26.05

\begin{tabular}{|c|c|c|c|c|c|}
\hline $\begin{array}{l}\text { Lugar } \\
\text { en el } \\
\text { ranking }\end{array}$ & $\begin{array}{c}\text { Nombre } \\
\text { aplicación }\end{array}$ & Desarrollador & $\begin{array}{c}\text { Fecha } \\
\text { actualización }\end{array}$ & $\begin{array}{c}\text { Clasificación } \\
\text { de } \\
\text { contenido }\end{array}$ & Tipología \\
\hline 3 & $\begin{array}{c}\text { Candy } \\
\text { crush saga }\end{array}$ & King.com & $\begin{array}{c}21 \text { octubre } \\
2013\end{array}$ & Todos & $\begin{array}{c}+ \\
100.000 .000\end{array}$ \\
\hline 6 & $\begin{array}{c}\text { Papa pear } \\
\text { saga }\end{array}$ & King.com & $\begin{array}{c}22 \text { octubre } \\
2013\end{array}$ & Todos & +500.000 \\
\hline 8 & Pou & Zakeh & $\begin{array}{c}16 \text { octubre } \\
2013\end{array}$ & Todos & $\begin{array}{c}+ \\
100.000 .000\end{array}$ \\
\hline 10 & $\begin{array}{c}\text { Bola de } \\
\text { salto }\end{array}$ & Moon jumper & $\begin{array}{c}26 \\
\text { septiembre } \\
2013\end{array}$ & Todos & +1.000 .000 \\
\hline 17 & $\begin{array}{c}\text { Pet rescue } \\
\text { saga }\end{array}$ & King.com & $\begin{array}{c}22 \text { octubre } \\
2013\end{array}$ & Todos & $\begin{array}{c}+ \\
10.000 .000\end{array}$ \\
\hline 20 & $\begin{array}{c}\text { Where's } \\
\text { my water } \\
2 ?\end{array}$ & Disney & $\begin{array}{c}24 \text { octubre } \\
2013\end{array}$ & $\begin{array}{c}\text { Nivel de } \\
\text { madurez bajo }\end{array}$ & +1.000 .000 \\
\hline 21 & $\begin{array}{l}\text { Gru. Mi } \\
\text { villano } \\
\text { favorito }\end{array}$ & Gameloft & $\begin{array}{c}24 \text { octubre } \\
2013\end{array}$ & Todos & $\begin{array}{c}+ \\
50.000 .000\end{array}$ \\
\hline 24 & $\begin{array}{l}\text { Beard } \\
\text { salon - } \\
\text { free } \\
\text { games }\end{array}$ & $6677 \mathrm{~g} . \mathrm{com}$ & $\begin{array}{c}28 \\
\text { septiembre } \\
2013\end{array}$ & Todos & +1.000 .000 \\
\hline 25 & $\begin{array}{c}\text { Crazy } \\
\text { parking } \\
\text { car king } \\
\text { 3D }\end{array}$ & Chi chi games & $\begin{array}{c}10 \text { octubre } \\
2013\end{array}$ & Todos & +1.000 .000 \\
\hline 26 & $\begin{array}{l}\text { Subway } \\
\text { surfers }\end{array}$ & Kiloo & $\begin{array}{c}10 \text { octubre } \\
2013\end{array}$ & $\begin{array}{c}\text { Nivel de } \\
\text { madurez bajo }\end{array}$ & $\begin{array}{c}+ \\
100.000 .000\end{array}$ \\
\hline
\end{tabular}

Tabla 2. Aplicaciones Android gratuita

\subsection{Selección de las variables a analizar}

Dentro de los estudios sobre audiencias infantiles que se han consultado, existen algunos aspectos que preocupan a los investigadores, así como determinadas variables que determinan la adecuación del contenido al nivel madurativo del niño, los peligros de exposición a los contenidos o, dentro del entorno Internet, si la navegación a lo largo de estos contenidos genera algún tipo de interacción con otros usuarios conocidos o desconocidos.

Por tanto, las variables seleccionadas intentan verificar la adecuación o no de las aplicaciones y sus contenidos, para los menores del rango de edad mencionado

- Específicamente infantil: Hace referencia a la realidad argumental del contenido, independientemente de la calificación adjudicada.

- Calificación de los contenidos: Si, esta aparece claramente, especificado antes de descargarse la aplicación, y si de hacerlo, está en consonancia con el código de regulación de calificación por edad de videojuegos (MTAS, 2008: 21), ya es la que más se podría acercar a las aplicaciones, puesto que aun no existe uno ex profeso para las mismas. 
- Contiene Publicidad y si es específica infantil y la marca: En la mayoría de las aplicaciones gratuitas, la publicidad se constituye como el principal modelo de negocio para los desarrolladores. Por tanto, en el caso de que exista publicidad, si ésta es infantil o no y qué tipo de productos anuncian.

- Petición datos personales y cuales: Si, para avanzar en los objetivos, pasar de versiones gratuitas a Premium (pago) o compartir resultados on line, se solicitan datos personales de los menores.

- Interacción con redes sociales y cuales: Si, existen hipervínculos para compartir determinados contenidos a través de las redes sociales, aún a sabiendas de que en todas, existe un mínimo de edad recomendada para ingresar.

- Permite juego con otros usuarios y si pertenecen a una lista de distribución privada del usuario o a listas abiertas: Si, las aplicaciones tienen un sistema de contactos con usuarios on line que fomente la interacción con el círculo de amistades del niño o, por el contario, con usuarios desconocidos. Teniendo en cuenta el hecho de que muchas de las aplicaciones cuentan con usuarios de todas las edades, es importante conocer la facilidad de exposición del menor no conoce.

- Facilita el acceso a otras descargas: Si, la aplicación es en sí misma una pasarela a descargas de otras aplicaciones del mismo desarrollador que no tienen porque ir en consonancia con las calificaciones de edad a través de la cual se accedió y en el caso de que así sea, si son de pago.

- Informa adecuadamente de los permisos de descargas: Cuando se descarga la aplicación, si, deja claro y en un lenguaje sencillo, los permisos que se conceden a la misma, en cuanto a privacidad y uso datos del dispositivo móvil desde el que se accede.

- Colores predominantes utilizados en la grafica: Nivel de luminosidad, brillo y saturación de los colores, son importantes a la hora de captar la atención de los más pequeños, susceptibles por inclinación y edad, a colores brillantes y muy saturados.

- Predominio de los ángulos / curvas en los gráficos. Los ángulos y las curvas determinan en los gráficos, el nivel de agresividad o tranquilidad, que puede producir en los menores, siendo preferibles los gráficos con formas redondeadas frente a aquellas que contienen más aristas.

- Movimiento lento/rápido de los gráficos: La rapidez del juego puede inducir a que los niños se pongan más nerviosos o a generar mayor adicción.

\section{RESULTADOS}

A partir del análisis de la información recogida en las diferentes aplicaciones, estos son los resultados obtenidos.

En líneas generales, las APP que han sido analizadas no son para niños, es decir, a pesar de contener unas graficas animadas que podrían dar por sentado que los contenidos se dirigen a un público infantil, estos contenidos no están creados específicamente para niños. En el caso de Android, si bien es cierto que la clasificación no discrimina en edad y especifica que va dirigida a todos, son los que llevan una clasificación de "nivel de madurez bajo" los que realmente tienen un perfil infantil. Sin embargo en iOs es la calificación de mayor de 4 años la que da paso una indefinición de públicos o usuarios, puesto que significa que niños de 4 años están preparados para acceder a la aplicación y todo lo que ésta conlleva.

A pesar de que la edad legal mínima para poder hacerse un perfil en Facebook es de 14 años (9) en España y de 13 años para el resto del mundo, resulta cuando menos chocante el hecho de que la mayoría de las aplicaciones invitan a los usuarios a conectarse a la red social y compartir sus resultados con sus amigos, incentivando estas acciones en alguno de los caso, con la obtención de puntos extra o herramientas para avanzar en el juego, como es el caso de Where is my water que, además, va dirigida a un usuario de nivel de madurez bajo y cuyo argumento es específicamente infantil.

En la mayor parte de las aplicaciones de Google play no son requeridos datos personales aparte de los propios que ya se dan en los permisos de la aplicación. Es decir, que priman los del usuario registrado en Google play 
que a su vez es el dueño del dispositivo. Sin embargo, y pese a que pocos permiten el juego on line o el contacto con otros usuarios, el hecho de fomentar el acceso las redes sociales, puede generar una vía de contacto con otro usuarios dentro de un entorno poco seguro para el menor.

En iOs sin embargo, sí que existe mayor petición de datos personales no solo para acceder a otras redes sociales, sino para el Game Center (10), aplicación instalada por defecto en el dispositivo, que comparte el perfil de usuario en la mayoría de las aplicaciones de juego que se descargan en el iPad.

Las aplicaciones gratuitas no existen, es decir existen versiones de prueba más o menos completas, pero para poder avanzar en el reto que supone la consecución de pantallas, es necesario pagar por completar el acceso a las herramientas. Es aquí donde el niño se encuentra con conceptos intangibles para él y con los que no está familiarizado, como es la compra on line y en donde puede llegar a usar toda su capacidad de persuasión hacia sus progenitores.

En general los gráficos contienen colores muy saturados y brillantes (rosas, anaranjados, amarillos, azules, verdes...) con predominio de los colores planos y continuos, frente a los que tienen apariencia de 3D. El predominio de los ángulos está unido a aplicaciones en los que predomina la realidad o un acercamiento a similitud con la misma (FIFA, CSR classics, Crazy parking car 3D o Subway surfers). A partir de aquí hay una asociación directamente proporcional entre este tipo de gráficos con el movimiento con el que se produce el juego, siendo más rápidos y frenéticos que en los juegos más ingenuos.

\subsection{Aplicaciones para Android}


http://dx.doi.org/10.12795/Ambitos.2014.i26.05

\begin{tabular}{|c|c|c|c|c|c|}
\hline & $\begin{array}{l}\text { Candy } \\
\text { crush }\end{array}$ & Papa pear & Pou & $\begin{array}{c}\text { Bola de } \\
\text { salto }\end{array}$ & Pet rescue \\
\hline $\begin{array}{l}\text { Especifleamente } \\
\text { Infantil }\end{array}$ & No & No & No & No & No \\
\hline $\begin{array}{l}\text { Califleación de } \\
\text { los contenidos }\end{array}$ & Todos & Todos & Todos & Todos & Todos \\
\hline $\begin{array}{l}\text { Contlene } \\
\text { Publlcldad }\end{array}$ & No & No & No & Si & No \\
\hline $\begin{array}{l}\text { ¿Especifica } \\
\text { Infantill? }\end{array}$ & HOH & & & No, Google & W \\
\hline Marca & $\mathbb{W} U 1111$ & $\mathbb{1} 1 / 1 / 1 / 1 / 1$ & $\mathbb{1 1} 1$ & Play & WU \\
\hline $\begin{array}{l}\text { Peticlón datos } \\
\text { personales } \\
\text { ¿Qú́ datos? } \\
\end{array}$ & No & No & No & No & No \\
\hline $\begin{array}{c}\text { Interacelón con } \\
\text { redes soclales } \\
\text { ¿Cuáles? }\end{array}$ & $\begin{array}{c}\text { Si con } \\
\text { Facebook }\end{array}$ & $\begin{array}{c}\text { Si con } \\
\text { Facebook }\end{array}$ & No & No & $\begin{array}{c}\text { Si, } \\
\text { Facebook }\end{array}$ \\
\hline $\begin{array}{l}\text { Permite Juego } \\
\text { con otros } \\
\text { usuarlos } \\
\text { ¿Conocldos? }\end{array}$ & No & No & No & No & No \\
\hline $\begin{array}{l}\text { Facillta el } \\
\text { acceso a otras } \\
\text { descargas } \\
\end{array}$ & No & No & SI & Si & Si \\
\hline $\begin{array}{l}\text { Esas descargas } \\
\text { son de pago }\end{array}$ & 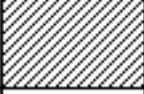 & W & SI & No & Si \\
\hline $\begin{array}{l}\text { Informa } \\
\text { adecuadamente } \\
\text { de los permlsos } \\
\text { de descargas }\end{array}$ & SI & SI & SI & SI & $\mathrm{S} \mid$ \\
\hline $\begin{array}{c}\text { Colores } \\
\text { predominantes } \\
\text { utillzados en la } \\
\text { grafica }\end{array}$ & $\begin{array}{l}\text { Brillantes } \\
\text { y muy } \\
\text { saturados } \\
\text { y con } \\
\text { volumen }\end{array}$ & $\begin{array}{c}\text { Colores } \\
\text { brillantes, } \\
\text { saturación } \\
\text { media y } \\
\text { continuos }\end{array}$ & $\begin{array}{c}\text { Colores } \\
\text { continuos } \\
\text { y con } \\
\text { brillo y } \\
\text { saturación } \\
\text { media }\end{array}$ & $\begin{array}{c}\text { Colores } \\
\text { poco } \\
\text { saturados y } \\
\text { planos }\end{array}$ & $\begin{array}{c}\text { Colores con } \\
\text { saturación } \\
\text { media y } \\
\text { volumen }\end{array}$ \\
\hline $\begin{array}{l}\text { Predominlo de } \\
\text { los ángulos I } \\
\text { curvas en los } \\
\text { gráflcos }\end{array}$ & Curvas & $\begin{array}{l}\text { Dibujos } \\
\text { redondeados } \\
\text { e ingenuos }\end{array}$ & Curvas & $\begin{array}{c}\text { Gráficos } \\
\text { pobres y } \\
\text { predominio } \\
\text { de ángulos }\end{array}$ & Curvas \\
\hline $\begin{array}{l}\text { Movimiento } \\
\text { lentolrápldo de } \\
\text { los gráfleos }\end{array}$ & Lento & Rápido & Lentos & Lento & Lento \\
\hline
\end{tabular}


http://dx.doi.org/10.12795/Ambitos.2014.i26.05

\begin{tabular}{|c|c|c|c|c|c|}
\hline & $\begin{array}{c}\text { Where's } \\
\text { my water } \\
2 ?\end{array}$ & $\begin{array}{l}\text { Gru. Mi } \\
\text { villano } \\
\text { favorito }\end{array}$ & $\begin{array}{l}\text { Beard } \\
\text { salon - } \\
\text { free } \\
\text { games }\end{array}$ & $\begin{array}{c}\text { Crazy } \\
\text { parking car } \\
\text { king 3D }\end{array}$ & $\begin{array}{l}\text { Subway } \\
\text { surfers }\end{array}$ \\
\hline $\begin{array}{c}\text { Especificamente } \\
\text { Infantll }\end{array}$ & Si & No & No & No & Si \\
\hline $\begin{array}{l}\text { Callficación de } \\
\text { los contenido }\end{array}$ & $\begin{array}{l}\text { Nivel de } \\
\text { madurez } \\
\text { bajo }\end{array}$ & Todos & Todos & Todos & $\begin{array}{l}\text { Nivel de } \\
\text { madurez } \\
\text { bajo }\end{array}$ \\
\hline $\begin{array}{l}\text { Contlene } \\
\text { Publleidad }\end{array}$ & No & Si & Si & Si & No \\
\hline $\begin{array}{c}\text { ¿Especiflea } \\
\text { InfantIII? } \\
\text { Marca }\end{array}$ & & Si, Ice Age & $\begin{array}{c}\text { No, FIFA } \\
12\end{array}$ & $\begin{array}{c}\text { App de } \\
\text { Contactos } \\
\text { POF y Line }\end{array}$ & \\
\hline $\begin{array}{l}\text { Petición datos } \\
\text { personales } \\
\text { ¿Qué datos? }\end{array}$ & No & No & No & No & No \\
\hline $\begin{array}{l}\text { Interacción con } \\
\text { redes soclales } \\
\text { ¿Cuáles? }\end{array}$ & $\begin{array}{c}\mathrm{SI} \text {, con } \\
\text { Facebook }\end{array}$ & $\begin{array}{c}\text { SI, con } \\
\text { Facebook y } \\
\text { Google + }\end{array}$ & $\begin{array}{c}\mathrm{Sl}, \infty \mathrm{n} \\
\text { Facebook }\end{array}$ & $\begin{array}{c}\mathrm{SI} \text {, con } \\
\text { Facebook }\end{array}$ & $\begin{array}{c}\text { SI, con } \\
\text { Facebook }\end{array}$ \\
\hline $\begin{array}{l}\text { Permite Juego } \\
\text { con otros } \\
\text { usuarlos } \\
\text { ¿Conocldos? }\end{array}$ & $\begin{array}{c}\text { SI, de } \\
\text { Facebook }\end{array}$ & $\mathrm{SI}$ & No & No & No \\
\hline $\begin{array}{c}\text { Facillita el } \\
\text { acceso a otras } \\
\text { descargas }\end{array}$ & Si & $\mathrm{Si}$ & Si & SI & No \\
\hline $\begin{array}{l}\text { Esas descargas } \\
\text { son de pago }\end{array}$ & Si & Si & No & Si & No \\
\hline $\begin{array}{l}\text { Informa } \\
\text { adecuadamente } \\
\text { de los permisos } \\
\text { de descargas }\end{array}$ & Si & $\mathrm{Si}$ & SI & Si & Si \\
\hline $\begin{array}{l}\text { Colores } \\
\text { predominantes } \\
\text { utllizados en la } \\
\text { grafica }\end{array}$ & $\begin{array}{c}\text { Coloeres } \\
\text { brillantes, } \\
\text { saturación } \\
\text { media y } \\
\text { planos }\end{array}$ & $\begin{array}{c}\text { Brillantes y } \\
\text { Saturados } \\
\text { Con } \\
\text { volumen }\end{array}$ & $\begin{array}{l}\text { Colores } \\
\text { poco } \\
\text { saturados } \\
\text { y planos }\end{array}$ & $\begin{array}{c}\text { Gráficos } \\
\text { macabros, uso } \\
\text { de colores } \\
\text { saturados con } \\
\text { predominancia }\end{array}$ & $\begin{array}{c}\text { Saturación } \\
\text { media y } \\
\text { brillante. } \\
\text { Volumen }\end{array}$ \\
\hline
\end{tabular}

\begin{tabular}{|c|l|l|l|l|l|}
\hline $\begin{array}{c}\text { Predominlo de } \\
\text { los ángulos I } \\
\text { curvas en los } \\
\text { gráfleos }\end{array}$ & Curvas & Ángulos & Curvas & Ángulos & Ángulos \\
\hline $\begin{array}{c}\text { Movimiento } \\
\text { lento/rápldo de } \\
\text { los gráfleos }\end{array}$ & Lento & $\begin{array}{c}\text { Rápido y } \\
\text { adictivo }\end{array}$ & Lento & Rápido & Rápidos \\
\hline
\end{tabular}

\subsection{Aplicaciones para iOs}


http://dx.doi.org/10.12795/Ambitos.2014.i26.05

\begin{tabular}{|c|c|c|c|c|c|}
\hline & $\begin{array}{l}\text { Turbo } \\
\text { racing } \\
\text { league }\end{array}$ & $\begin{array}{c}\text { Pet rescue } \\
\text { saga }\end{array}$ & $\begin{array}{c}\text { Crazy shave } \\
\text { - free } \\
\text { games }\end{array}$ & $\begin{array}{l}\text { Nose } \\
\text { doctorl }\end{array}$ & $\begin{array}{l}\text { Candy } \\
\text { crush } \\
\text { saga }\end{array}$ \\
\hline $\begin{array}{l}\text { Especificamento } \\
\text { infantil }\end{array}$ & No & No & $\mathrm{Si}$ & Si & No \\
\hline $\begin{array}{l}\text { Calificación de } \\
\text { los contenidos }\end{array}$ & + 4 aก̃os & + 4 aก̃os & $\begin{array}{c}\text { + } 4 \text { años } \\
\text { (pensada } \\
\text { para niños } \\
\text { de } 6 \cdot 8 \text { años) }\end{array}$ & $\begin{array}{c}\text { + } 4 \text { años } \\
\text { (pensada } \\
\text { para niños de } \\
\text { 6-8 años) }\end{array}$ & +4 aก̃os \\
\hline $\begin{array}{l}\text { Contione } \\
\text { Publicidad }\end{array}$ & No & No & $\begin{array}{l}\text { Del propio } \\
\text { desarrollador }\end{array}$ & $\begin{array}{l}\text { Del propio } \\
\text { desarrollador }\end{array}$ & No \\
\hline $\begin{array}{l}\text { ¿Especifica } \\
\text { infantil? } \\
\text { Marca }\end{array}$ & {$\left[\begin{array}{r}\sigma \\
y\end{array}\right.$} & $\begin{array}{r}\sigma \\
y\end{array}$ & No & No & {$\left[\begin{array}{r}\tau \\
\tau\end{array}\right.$} \\
\hline $\begin{array}{l}\text { Petición datos } \\
\text { personalos } \\
\text { ¿Quó datos? }\end{array}$ & $\begin{array}{l}\text { Nombre de } \\
\text { usuario, } \\
\text { solicitud de } \\
\text { registro on } \\
\text { redes } \\
\text { sociales, } \\
\text { acceso a } \\
\text { las fotos } \\
\text { del } \\
\text { dispositivo } \\
\text { y datos del } \\
\text { Gamo } \\
\text { Center del } \\
\text { dispositivo }\end{array}$ & $\begin{array}{l}\text { Para } \\
\text { compras }\end{array}$ & $\begin{array}{l}\text { Acceso a } \\
\text { fotos del } \\
\text { dispositivo }\end{array}$ & No & $\begin{array}{l}\text { Registro } \\
\text { en redes } \\
\text { sociales }\end{array}$ \\
\hline $\begin{array}{l}\text { Interaceión con } \\
\text { redos sociales } \\
\text { ¿Cuáles? }\end{array}$ & $\begin{array}{c}\text { Si } \\
\text { Facebook } \\
\text { y Twitter } \\
\text { para } \\
\text { conseguir } \\
\text { puntos }\end{array}$ & $\begin{array}{c}\text { Si, } \\
\text { Facebook }\end{array}$ & $\begin{array}{c}\text { No, aunque } \\
\text { invita a } \\
\text { valorar al } \\
\text { contenido }\end{array}$ & No & $\begin{array}{c}\text { Si, } \\
\text { Facebook } \\
\text { para } \\
\text { compartir } \\
\text { resultados }\end{array}$ \\
\hline $\begin{array}{l}\text { Permite juego } \\
\text { con otros } \\
\text { usuarios } \\
\text { ¿Conocidos? }\end{array}$ & No & $\begin{array}{c}\text { Permite } \\
\text { compartir } \\
\text { puntuación } \\
\text { con amigos } \\
\text { en Facobook }\end{array}$ & No & No & $\begin{array}{c}\text { Permite } \\
\text { compartir } \\
\text { puntuación } \\
\text { con } \\
\text { amigos en } \\
\text { Facebook } \\
\text { y } \\
\text { solicitarles } \\
\text { vidas }\end{array}$ \\
\hline $\begin{array}{l}\text { Facilita ol } \\
\text { acceso a otras } \\
\text { descargas }\end{array}$ & $\begin{array}{c}\text { Si, } \\
\text { compras } \\
\text { para } \\
\text { conseguir } \\
\text { puntos }\end{array}$ & $\begin{array}{c}\text { Si, compras } \\
\text { para } \\
\text { conseguir } \\
\text { puntos }\end{array}$ & $\begin{array}{c}\text { Si, compras } \\
\text { para } \\
\text { desbloquear } \\
\text { personajes. } \\
\text { Utiliza un } \\
\text { sistema do } \\
\text { desbloqueo } \\
\text { manual }\end{array}$ & Si & $\begin{array}{c}\text { Si, } \\
\text { compras } \\
\text { para } \\
\text { conseguir } \\
\text { puntos }\end{array}$ \\
\hline
\end{tabular}


http://dx.doi.org/10.12795/Ambitos.2014.i26.05

\begin{tabular}{|c|c|c|c|c|c|}
\hline $\begin{array}{l}\text { Esas descargas } \\
\text { son do pago }\end{array}$ & Si & Si & Si & $\begin{array}{c}\text { Si (para } \\
\text { desbloquear } \\
\text { personajos) / } \\
\text { no (los } \\
\text { juegos que } \\
\text { muestra para } \\
\text { descargas } \\
\text { son gratuitos) }\end{array}$ & Si \\
\hline $\begin{array}{l}\text { Informa } \\
\text { adecuadamente } \\
\text { do los permisos } \\
\text { de descargas }\end{array}$ & $\begin{array}{c}\text { No es } \\
\text { necesario } \\
\text { aceptar } \\
\text { para } \\
\text { descargar }\end{array}$ & $\begin{array}{c}\text { No es } \\
\text { necesario } \\
\text { aceptar para } \\
\text { descargar }\end{array}$ & $\begin{array}{c}\text { No es } \\
\text { necesario } \\
\text { aceptar para } \\
\text { descargar }\end{array}$ & $\begin{array}{c}\text { No es } \\
\text { necesario } \\
\text { aceptar para } \\
\text { descargar }\end{array}$ & $\begin{array}{c}\text { No es } \\
\text { necesario } \\
\text { aceptar } \\
\text { para } \\
\text { descargar }\end{array}$ \\
\hline $\begin{array}{l}\text { Colores } \\
\text { predominantes } \\
\text { utilizados en la } \\
\text { grafica }\end{array}$ & $\begin{array}{l}\text { Marrón, } \\
\text { azul, rojo, } \\
\text { blanoo, } \\
\text { negro, } \\
\text { amarillo }\end{array}$ & $\begin{array}{c}\text { Azul, } \\
\text { amarillo, } \\
\text { verde, } \\
\text { morado, } \\
\text { rojo, marrón }\end{array}$ & $\begin{array}{l}\text { Marrón, } \\
\text { morado, } \\
\text { azul, verdo, } \\
\text { amarillo }\end{array}$ & $\begin{array}{c}\text { Rojo, } \\
\text { amarillo, } \\
\text { azul, verdo, } \\
\text { marrón, } \\
\text { blanco }\end{array}$ & $\begin{array}{c}\text { Rosa, } \\
\text { verdo, } \\
\text { azul, } \\
\text { naranja, } \\
\text { amarillo, } \\
\text { rojo, } \\
\text { marrón }\end{array}$ \\
\hline $\begin{array}{l}\text { Prodominio de } \\
\text { los ángulos I } \\
\text { curvas en los } \\
\text { gráficos }\end{array}$ & Curvas & Curvas & Curvas & Curvas & Curvas \\
\hline $\begin{array}{l}\text { Movimionto } \\
\text { lonto/rápido de } \\
\text { los gráficos }\end{array}$ & Lento & Lento & Lento & Lento & Lento \\
\hline $\begin{array}{l}\text { Control del } \\
\text { sonido }\end{array}$ & $\begin{array}{c}\text { Sl, pero } \\
\text { poco } \\
\text { aocesible }\end{array}$ & Si & Si & $\begin{array}{c}\text { Si (se puede } \\
\text { apagar la } \\
\text { música de } \\
\text { fondo, pero } \\
\text { no los } \\
\text { sonidos que } \\
\text { genera al } \\
\text { juego) }\end{array}$ & $\begin{array}{l}\text { Si, del } \\
\text { sonido y } \\
\text { de la } \\
\text { música }\end{array}$ \\
\hline
\end{tabular}

\begin{tabular}{|c|c|c|c|c|c|}
\hline & $\begin{array}{l}\text { FIFA } 14 \\
\text { by EA } \\
\text { SPORTS }\end{array}$ & Libii hospital & $\begin{array}{c}\text { Cssr } \\
\text { classics }\end{array}$ & $\begin{array}{c}\text { Halloween } \\
\text { costume } \\
\text { party - } \\
\text { spooky } \\
\text { salon, spa } \\
\text { makeover } 8 \\
\text { dress up } \\
\end{array}$ & $\begin{array}{c}\text { Asphalt } 8 . \\
\text { Airbone }\end{array}$ \\
\hline $\begin{array}{l}\text { Especificamento } \\
\text { infantil }\end{array}$ & No & No & No & No & No \\
\hline $\begin{array}{l}\text { Calificación de } \\
\text { los contenidos }\end{array}$ & +4 aกี้อง & + 4 años & + 4 aก̃os & +4 aกี่อง & +4 aก๊os \\
\hline $\begin{array}{l}\text { Contiene } \\
\text { Publicidad }\end{array}$ & $\begin{array}{l}\text { Si, de la } \\
\text { FIFA }\end{array}$ & $\begin{array}{c}\text { Si, de otras } \\
\text { aplicaciones } \\
\text { del } \\
\text { desarrollador }\end{array}$ & $\begin{array}{c}\text { Si se } \\
\text { acepta el } \\
\text { visionado } \\
\text { de } \\
\text { publicidad, } \\
\text { se consigue } \\
\text { gasolina }\end{array}$ & $\begin{array}{c}\text { Si, de otras } \\
\text { aplicaciones } \\
\text { del } \\
\text { desarrollador } \\
\text { y externas }\end{array}$ & $\begin{array}{l}\text { Si, marcas } \\
\text { de coches }\end{array}$ \\
\hline $\begin{array}{l}\text { ¿Espocifica } \\
\text { infantil? } \\
\text { Marca }\end{array}$ & $\begin{array}{l}\text { No, } \\
\text { FIFA }\end{array}$ & No & $\begin{array}{c}\text { No } \\
\text { Game of } \\
\text { war, hay } \\
\text { day }\end{array}$ & 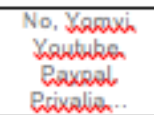 & No \\
\hline $\begin{array}{l}\text { Petición datos } \\
\text { porsonales } \\
\text { ¿Quó datos? }\end{array}$ & $\begin{array}{c}\text { Nombre } \\
\text { de } \\
\text { usuario, } \\
\text { acceso a } \\
\text { redes } \\
\text { sociales y } \\
\text { datos del } \\
\text { Game } \\
\text { Center del } \\
\text { dispositivo }\end{array}$ & No & $\begin{array}{l}\text { Si se hace } \\
\text { seguidor en } \\
\text { Twitter, lo } \\
\text { da a me } \\
\text { gusta en } \\
\text { Facebook o } \\
\text { Twittea, so } \\
\text { consigue } \\
\text { gasolina y } \\
\text { datos del } \\
\text { Game } \\
\text { Center del } \\
\text { dispositivo }\end{array}$ & $\begin{array}{l}\text { Acoeso a } \\
\text { fotos del } \\
\text { dispositivo }\end{array}$ & $\begin{array}{l}\text { Sl, datos } \\
\text { del Game } \\
\text { Center del } \\
\text { dispositivo }\end{array}$ \\
\hline $\begin{array}{l}\text { Interaceíón con } \\
\text { redos sociales } \\
\text { ¿Cuálos? }\end{array}$ & $\begin{array}{c}\text { Origin, } \\
\text { Youtube, } \\
\text { Facebook }\end{array}$ & No & $\begin{array}{l}\text { Facebook, } \\
\text { Twitter }\end{array}$ & No & Facebook \\
\hline $\begin{array}{l}\text { Permite juego con } \\
\text { otros usuarios } \\
\text { ¿Conocidos? }\end{array}$ & $\begin{array}{l}\text { Si, de } \\
\text { Origin }\end{array}$ & No & No & No & No \\
\hline $\begin{array}{l}\text { Facilita el acceso } \\
\text { a otras descargas }\end{array}$ & $\begin{array}{l}\text { Si, para } \\
\text { actualzar } \\
\text { plantillas }\end{array}$ & $\begin{array}{c}\text { Si, a la } \\
\text { versión } \\
\text { complata y } \\
\text { otros juegos } \\
\text { del } \\
\text { desarrollador }\end{array}$ & $\begin{array}{l}\text { Si, compras } \\
\text { dentro de la } \\
\text { aplicación }\end{array}$ & $\begin{array}{l}\text { Si, compras } \\
\text { dentro de la } \\
\text { aplicación }\end{array}$ & $\begin{array}{c}\text { Si, } \\
\text { compras } \\
\text { dentro de } \\
\text { la } \\
\text { aplicación }\end{array}$ \\
\hline
\end{tabular}




\begin{tabular}{|c|c|c|c|c|c|}
\hline $\begin{array}{l}\text { Esas doscargas } \\
\text { son de pago }\end{array}$ & No & $\begin{array}{l}\text { Si (la versión } \\
\text { completa) } / \\
\text { No (los otros } \\
\text { juegos del } \\
\text { desarrollador) }\end{array}$ & si & si & $\mathrm{Si}$ \\
\hline $\begin{array}{l}\text { Informa } \\
\text { adecuadamente } \\
\text { do los permisos } \\
\text { do descargas }\end{array}$ & $\begin{array}{l}\text { No es } \\
\text { necesario } \\
\text { aceptar } \\
\text { para } \\
\text { descargar }\end{array}$ & $\begin{array}{c}\text { No es } \\
\text { necosario } \\
\text { aceptar para } \\
\text { descargar }\end{array}$ & $\begin{array}{c}\text { No es } \\
\text { necesario } \\
\text { aceptar } \\
\text { para } \\
\text { descargar }\end{array}$ & $\begin{array}{c}\text { No es } \\
\text { necesario } \\
\text { aceptar } \\
\text { para } \\
\text { descargar }\end{array}$ & $\begin{array}{l}\text { No es } \\
\text { necesario } \\
\text { aceptar } \\
\text { para } \\
\text { descargar }\end{array}$ \\
\hline $\begin{array}{l}\text { Colores } \\
\text { predominantos } \\
\text { utilizados en la } \\
\text { grafica }\end{array}$ & $\begin{array}{l}\text { Rojo, } \\
\text { negro, } \\
\text { verde, } \\
\text { azul, gris }\end{array}$ & $\begin{array}{c}\text { Azul, rosa, } \\
\text { naranja, } \\
\text { amarillo, } \\
\text { marrón, } \\
\text { verde, } \\
\text { morado }\end{array}$ & $\begin{array}{c}\text { Rojo, } \\
\text { marrón, } \\
\text { gris, negro, } \\
\text { naranja, } \\
\text { amarillo }\end{array}$ & $\begin{array}{l}\text { Verde, } \\
\text { morado, } \\
\text { naranja, } \\
\text { amarillo, } \\
\text { azul, rosa }\end{array}$ & $\begin{array}{c}\text { Amarillo, } \\
\text { negro, } \\
\text { rojo, azul, } \\
\text { verdo, } \\
\text { marrón }\end{array}$ \\
\hline $\begin{array}{l}\text { Prodominio do los } \\
\text { ángulos / curvas } \\
\text { on los gráficos }\end{array}$ & Angulos & Curvas & Ángulos & Curvas & Angulos \\
\hline $\begin{array}{l}\text { Movimionto } \\
\text { lontolrápido do } \\
\text { los gráficos }\end{array}$ & Rápido & Lento & Rápido & Lento & Rápido \\
\hline $\begin{array}{l}\text { Control del } \\
\text { sonido }\end{array}$ & $\begin{array}{l}\mathrm{SI} \text {, muy } \\
\text { completo }\end{array}$ & No & Si & Si & $\begin{array}{l}\mathrm{Si} \text {, muy } \\
\text { complato }\end{array}$ \\
\hline
\end{tabular}

\section{CONCLUSIONES}

No existe una adhesión de criterios para conocer si realmente las aplicaciones ofertadas en las diferentes tiendas son de uso infantil o no. La calificación a la que se someten es muchas veces incongruente o laxa, generando confusión en el niño. Por tanto el primer filtro a aplicar debe ser la propia experiencia del adulto, que debe verificar sin lugar a dudas lo apropiado del contenido, más allá de las apetencias del niño, que no es lo suficientemente maduro para realizar un análisis adecuado.

En segundo lugar, se debe dar la suficiente formación para que el niño decida si debe o no jugar con ciertas aplicaciones, y entender qué es lo que se le pide en todo momento; por ese motivo es necesario la presencia de los padres al menos durante los primeros momentos de uso de las aplicaciones. De este modo, guiar al menor en el uso correcto y en el entendimiento de lo que nos pide la aplicación.

Verificar si los contenidos complementarios; publicidad, compartir logros o imágenes con otros usuarios y permisos de privacidad son adecuados a la edad del menor. El hecho de que los dispositivos móviles sean táctiles, deriva en que muchas veces los niños pinchan sin darse cuenta en contenidos inadecuados.

La mayor parte de las aplicaciones educativas y adecuadas al momento evolutivo de los niños son de pago, lo que supone un freno a la hora de instalarlas. El volumen de descargas frente a las gratuitas es muy inferior. En este sentido, se debe valorar si queremos o no dejar el dispositivo a los niños. La calidad de los contenidos que descargamos y a los que acceden los niños, puede significar la diferencia entre niños más formados o menos formados.

Por último, es importante replantear, por parte de los fabricantes la clasificación de los contenidos de las APP y contar con sitios específicos para los niños y padres, de forma que sea más fácil valorar adecuadamente lo que se va a instalar en el dispositivo.

\section{REFERENCIAS BIBLIOGRÁFICAS}

Area Moreira, M. "La alfabetización en la sociedad digital" en Fundación Telefónica (2012): Alfabetización digital y competencias informacionales. Barcelona. Ariel.

Arenas, P. (2011): Cuidado: el tecnoestrés avanza. 20minutos, 17/05/2011.

Bringué, X. y Sádaba, C. (2009): La generación interactiva en España. Niños y adolescentes ante las pantallas. Barcelona. Ariel. 
Buxarrais, M. R. (2011): La Influencia de las TIC en la vida cotidiana de las familias y los valores de los adolescentes Universitat de Barcelona. [en línea]. 12 septiembre 2013 [Consulta: 12 septiembre 2013]. <http://oed.ub.edu/>

Chaval.es. (2013). Siete consejos de expertos para escoger las mejores Apps para tus hijos . [en línea]. 9 septiembre 2013 [Consulta: 9 septiembre 2013]. <http://www.chaval.es/chavales/enterate/software/sieteconsejos-de-expertos-para-escoger-las-mejores-apps-para-tus-hijos>

Chaval.es. (2013). ¿Le compro un smartphone al niño? Pros y contras de que un menor de edad tenga móvil propio. [en línea]. 8 octubre 2013 [Consulta: 8 octubre 2013].

<http://www.chaval.es/chavales/experiencias/educadores/\%C2\%BFle-compro-un-smartphone-al-nino>

Common Sense Media. (2013). Zero to Eight. Children's media use in America 2013. [en línea]. 20 octubre 2013 [Consulta: 20 octubre 2013]. <http://www.commonsensemedia.org/sites/default/files/research/zero-to-eight2013.pdf>

ComScore. (2013). Spain Digital Future in Focus. [en línea]. 12 septiembre 2013 [Consulta: 15 octubre 2013]. <http://www.comscore.com/Insights/Blog/2013_Digital_Future_in_Focus_Series>

Fumero Reverón, A. y Espiritusanto Nicolás, Ó. (2012). Jóvenes e infotecnologías. Injuve.

Gamero, R. (2010). Matizando la definición de "nativos digitales". Nota Enter p.168.

INE. (2013). Encuesta sobre equipamiento y uso de Tecnologías de Información y Comunicación en los Hogares (TIC-H). [en línea]. 8 octubre 2013 [Consulta: 8 octubre 2013]. < http://www.ine.es/prensa/np803.pdf>

Nielsen. (2012). American Families see tablets as playmate, teacher and babysitter. [en línea]. 8 octubre 2013 [Consulta: 8 octubre 2013]. <http://www.nielsen.com/us/en/newswire/2012/american-families-see-tablets-asplaymate-teacher-and-babysitter.html>

NTT Docomo - GSMA. (2011). Utilización de los teléfonos móviles por los niños. Estudio comparativo Internacional 2011.

Orange - Inteco. (2011). Estudio sobre hábitos seguros en el uso de smartphones por los niños y adolescentes españoles.

Prensky, M. (2001). Digital Natives, Digital Inmigrants. On the Horizon. MCB University Press, Vol. 9 № 5.

TABinnovation. 2013. Tabletas infantiles: ventajas y modelos más solicitados. [en línea]. 10 octubre 2013 [Consulta: 10 octubre 2013]. <http://www.tabinnovation.com/tabletas-infantiles/>

Xataca. (2013). Gartner: las ventas de tablets crecerán un $70 \%$ en 2013, los ordenadores caerán un $7 \%$. [en línea]. 8 octubre 2013 [Consulta: 8 octubre 2013]. <http://www.xataka.com/tablets/gartner-las-tablets-creceranun-70-en-2013-los-ordenadores-caeran-un-7>

\section{Breve semblanza de las autoras}

María Sánchez Martínez es doctora en Comunicación por la Universidad CEU San Pablo, profesora de 'Tecnología y Nuevos Medios' y 'Comunicación Estratégica Online' en la Facultad de Humanidades y Ciencias de la Comunicación de Universidad CEU San Pablo. Dirige el Master de Comunicación Multimedia Tracor/CEU. Es miembro del Grupo de Investigación en Convergencia de Medios (INCIRTV). Es profesora visitante en Regent's University, Londres y en LUMSA, Roma.

Teresa Barceló Ugarte es doctora en Ciencias de la Comunicación. Profesora de Televisión y del Máster en Periodismo Cultural de la Facultad de Humanidades y Ciencias de la Comunicación de la Universidad CEU San Pablo y Coordinadora del Grado en Comunicación Digital. Es miembro del grupo de investigación INCIRTV y del 
Observatorio del Ocio y el Entretenimiento Digital (OCENDI). Su línea de investigación se centra en las tecnologías audiovisuales.

(1) http://www.comscore.com/Insights/Blog/2013_Digital_Future_in_Focus_Series

(2) A los 10 años un 26,1 \% ya dispone de su primer teléfono móvil y a los 15 años ya son el 90,2 \% (INE, 2013). En el estudio Orange-Inteco (2011) se situaba en 11 años la edad de acceso al primer smartphone.

(3) http://www.chaval.es/chavales/experiencias/educadores/\%C2\%BFle-compro-un-smartphone-al-nino

(4) http://www.xataka.com/tablets/gartner-las-tablets-creceran-un-70-en-2013-los-ordenadores-caeran-un-7

(5) http://www.chaval.es/chavales/enterate/software/siete-consejos-de-expertos-para-escoger-las-mejores-appspara-tus-hijos

(6) http://www.tabinnovation.com/tabletas-infantiles/

(7) American Families See Tablets as Playmate, Teacher and Babysitter http://www.nielsen.com/us/en/newswire/2012/american-families-see-tablets-as-playmate-teacher-andbabysitter.html

(8) Recogidas la semana del 14 al 20 de octubre de 2013 para poder tenerlas lo más actualizadas posible, debido a la rapidez con que cambian su posición en el ranking.

(9) Herramientas para padres y educadores http://es-es.facebook.com/help/441374602560317/

(10) Game Center de Apple España http://www.apple.com/es/game-center/

Ámbitos. Revista Internacional de Comunicación, n.26, año 2014, tercer trimestre (otoño). 